\title{
Penicillium araracuarense sp. nov., Penicillium elleniae sp. nov., Penicillium penarojense sp. nov., Penicillium vanderhammenii sp. nov. and Penicillium wotroi sp. nov., isolated from leaf litter
}

Correspondence Jos Houbraken j.houbraken@cbs.knaw.nl

\author{
Jos Houbraken, ${ }^{1}$ Carlos A. López-Quintero, ${ }^{2}$ Jens C. Frisvad, ${ }^{3}$ \\ Teun Boekhout, ${ }^{1}$ Bart Theelen, ${ }^{1}$ Ana Esperanza Franco-Molano ${ }^{2}$ \\ and Robert A. Samson ${ }^{1}$ \\ ${ }^{1}$ CBS-KNAW Fungal Biodiversity Centre, PO Box 85167, 3508 AD Utrecht, The Netherlands \\ ${ }^{2}$ Laboratorio de Taxonomia y Ecología de Hongos (TEHO), Instituto de Biología, Universidad de \\ Antioquia, PO Box 1226, calle 67 \# 53-108 Medellin, Colombia \\ ${ }^{3}$ Center for Microbial Biotechnology, Department of Systems Biology, Building 221, Technical \\ University of Denmark, DK-2800 Kgs. Lyngby, Denmark
}

\section{INTRODUCTION}

The vegetation of the tropical lowland forest along the Caquetá River, Colombia, has been extensively studied and many ecological investigations of this area have been

Abbreviations: ML, maximum-likelihood; MP, maximum-parsimony.

The GenBank/EMBL/DDBJ accession numbers for the $\beta$-tubulin and ITS gene sequences of the type strains of $P$. araracuarense sp. nov., $P$. elleniae sp. nov., $P$. penarojense sp. nov., $P$. vanderhammenii sp. nov. and $P$. wotroi sp. nov. are GU981642 and GU981597, GU981663 and GU981612, GU981646 and GU981570, GU981647 and GU981574, and GU981637 and GU981591, respectively.

The Mycobank (http://www.mycobank.org) accession numbers for $P$. araracuarense sp. nov., $P$. elleniae sp. nov., $P$. penarojense sp. nov., $P$. vanderhammenii sp. nov. and $P$. wotroi sp. nov. are MB51825, MB518028, MB518024, MB518027 and MB518026, respectively.

Supplementary figures are available with the online version of this paper. conducted. These studies show that the soils of these forests are poor in nutrients, but that the diversity of tree species is among the highest in the world (Vester \& Cleef, 1998; Duivenvoorden \& Lips, 1998; Gentry, 1996; Sáenz, 1997). Micro-organisms play an important role in nutrient cycling and link the roots of trees with their environment, e.g. through the decomposition of leaf litter, such as lignin, cellulose and hemicelluloses, and through the uptake and immobilization of nutrients, nitrogen fixation, protection from pathogens and soil improvement (Killham, 1994; Richards, 1987). Decomposed leaf litter in such forest ecosystems is a major contributor to nutrient cycling, in which a large proportion of the nutrients from net primary production is returned to the forest floor (Maggs, 1985). Fungi play an important role in the decomposition of leaf litter due to their ability to penetrate dense substrates and enzymically break down macromolecular plant-derived 
material and they therefore tend to control the rate of decomposition (Osono \& Takeda, 2002; Wardle et al., 2004).

Numerous microfungi were isolated during a project to investigate the role of fungi during the regeneration processes of tropical lowland forests in the Caqueta area of the Colombian Amazon. During this study, microfungi were isolated from decomposing leaf litter, which had been incubated in leaf litter bags and placed on the forest floor for several months. A large number of different microfungi was isolated and the Penicillia were tentatively identified based on phenotype and extrolite data. Among these Penicillium isolates, several were not assignable to any described species. Many of these undescribed species were related to Penicillium janthinellum and Penicillium simplicissimum. Both of these species are phenotypically broadly circumscribed taxa and are often encountered in grassland and forest soil (Christensen et al., 2000). Raper \& Thom (1949) included both of these species in the P. janthinellum series, together with Penicillium daleae, Penicillium ochrochloron, Penicillium piscarium and Penicillium miczynskii. Members of this series share a fast growth rate and are variously branched, having monoverticillate to biverticillate asymmetrically and/or symmetrically branched conidiophores. Thirty years later, Pitt (1979) maintained $P$. janthinellum and P. simplicissimum as two separate species and placed nine and ten species, respectively, as synonyms with them. He noted that $P$. simplicissimum had an affinity with $P$. janthinellum and strains with intermediate properties occurred. Stolk \& Samson (1983) synonymized $P$. janthinellum with $P$. simplicissimum, made a connection with the teleomorphic species Eupenicillium javanicum and placed 26 species in synonymy. However, molecular data do not support the combination of all these species (Peterson, 2000). Furthermore, Tuthill et al. (2001) also showed that $P$. piscarium, Penicillium brasilianum and Penicillium pulvillorum are related, but distinct from $P$. simplicissimum, and that at least three undescribed species belong to this clade. Recently, another related species named Penicillium svalbardense was described from Arctic environments (Sonjak et al., 2007).

Combining phenotypic, molecular (ITS and partial $\beta$ tubulin gene sequences) and extrolite data, five novel species of the genus Penicillium are described here. In this study, species descriptions are provided, extrolite patterns are detailed and estimates for the phylogenetic relationships of these novel species are presented. Furthermore, using a phylogenetic approach, the relationship between $P$. simplicissimum and $P$. janthinellum and related species of the genera Penicillium and Eupenicillium is examined.

\section{MATERIAL AND METHODS}

Strains. Most strains were isolated from four collection sites: mature, 36-year-old and 48-year-old forest in Araracuara, Colombia, and from a dipterocarp forest in Peña Roja, Colombia. To study the microfungal community during decomposition, leaf litter bags filled with leaves from each collection site were deposited on the forest floor according to the method described by Aerts (1997), and the microfungal composition was analysed after 3 and 6 months of decomposition. To isolate the microfungal colonists, the strongly decayed litter was processed using the soil-washing method protocol of Gams \& Domsch (1967). A 4-6 g sample of litter fragments was washed three times with $500 \mathrm{ml}$ sterile distilled water by manual agitation for $5 \mathrm{~min}$. Small litter particles were placed onto $2 \%$ water agar and incubated for 7 days at $25{ }^{\circ} \mathrm{C}$. After incubation, subcultures were made on cornmeal agar (CMA, Difco) and pure cultures were maintained on slants of malt extract agar (MEA, Oxoid). The geographical and substrate origins of each isolate, together with the CBS-Fungal Biodiversity Centre and IBT (Technical University Denmark) accession numbers, are given in Table 1. Ex-type and additional cultures are maintained in the culture collection of the CBSFungal Biodiversity Centre, Utrecht, the Netherlands.

Morphology and extrolite profiles. For macroscopic analysis, isolates were inoculated in a three point pattern on Czapek yeast autolysate agar (CYA), malt extract agar (MEA), yeast extract sucrose agar (YES), oatmeal agar (OA), Dichloran $18 \%$ glycerol agar (DG18) and creatine sucrose agar (CREA). Colony diameters and other macroscopical features were recorded after 7 days of incubation at $25^{\circ} \mathrm{C}$ in darkness. The isolates on $\mathrm{OA}$ were incubated longer and followed in time for potential ascospore formation. Furthermore, growth curves were made on CYA agar incubated for 7 days at $27,30,33,36,37$ and $40{ }^{\circ} \mathrm{C}$. The isolates were examined for production of alkaloids reacting with Ehrlich reagent using a filter paper method (Lund, 1995). For microscopic examination, mounts of the strains were made in lactic acid from the MEA colonies. Minimum and maximum size values are presented for the conidia and ascospores. The mean and the standard deviation of these values were calculated (given in parentheses).

Extrolites. Isolates were grown on CYA and YES for 7-14 days and three or more plugs were cut out of a colony for extraction. Extractions were performed as described by Smedsgaard (1997). Extracts were analysed by HPLC with diode array UV-VIS detection using alkylphenone retention indices (Frisvad \& Thrane, 1987). Identification of the extrolites was conducted by comparison of the retention times and UV spectra with those of the analysis of standards or literature reports. Unknown metabolites were recorded and preliminary names were given to them.

Molecular studies: DNA extraction, PCR and sequencing. Mycelium and conidia were scraped from agar plates and transferred to $2 \mathrm{ml}$ collection tubes from the UltraClean Microbial DNA kit (MoBio Laboratories Inc.) and processed according to the manufacturer's instructions. Partial $\beta$-tubulin fragments were amplified using the primer combinations $\mathrm{T} 10$ and $\mathrm{Bt} 2 \mathrm{~b}$ or Bt2a and Bt2b (Glass \& Donaldson, 1995). The ITS regions including the $5.8 S$ were 
Table 1. Penicillium isolates used in this study

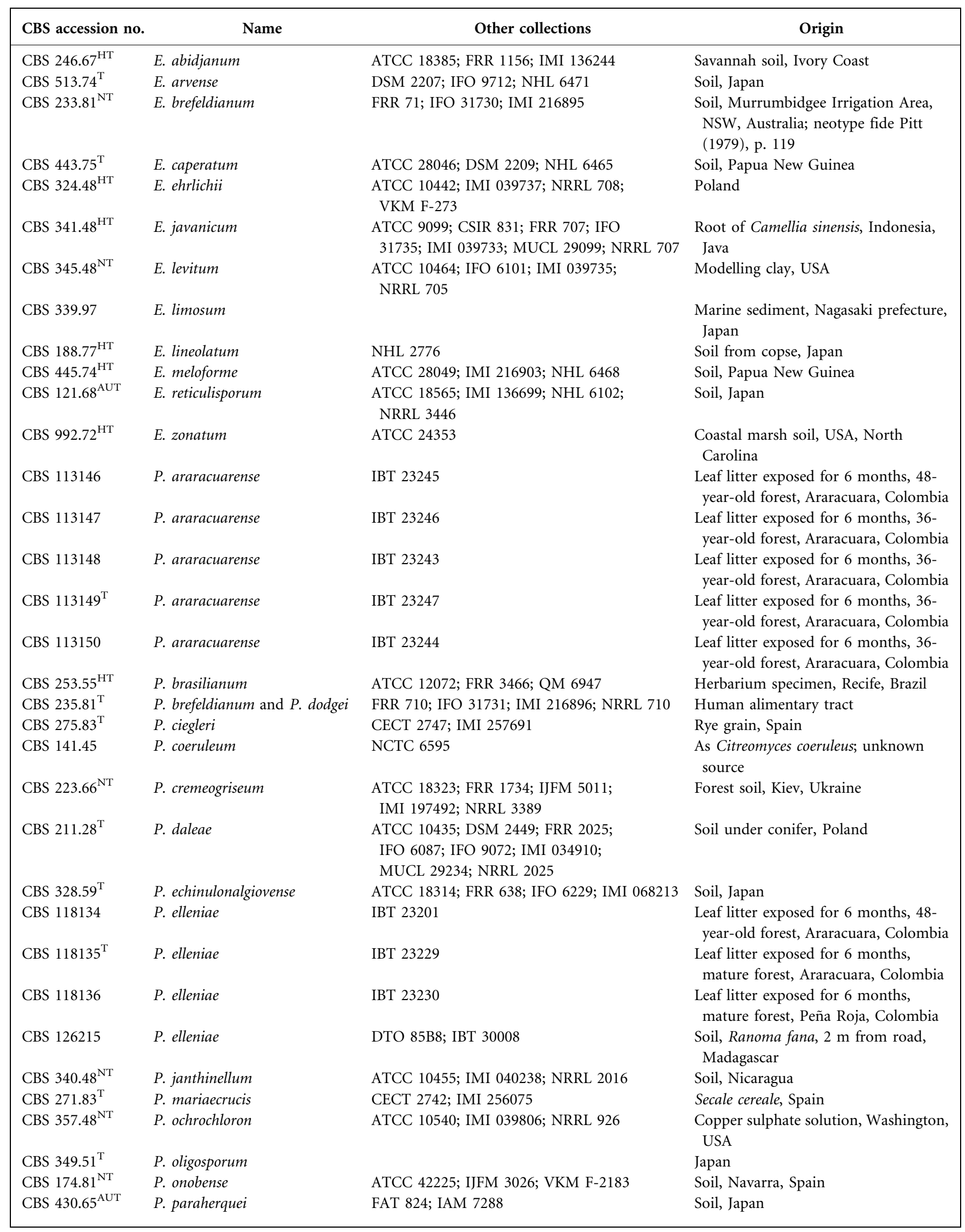


Table 1. cont.

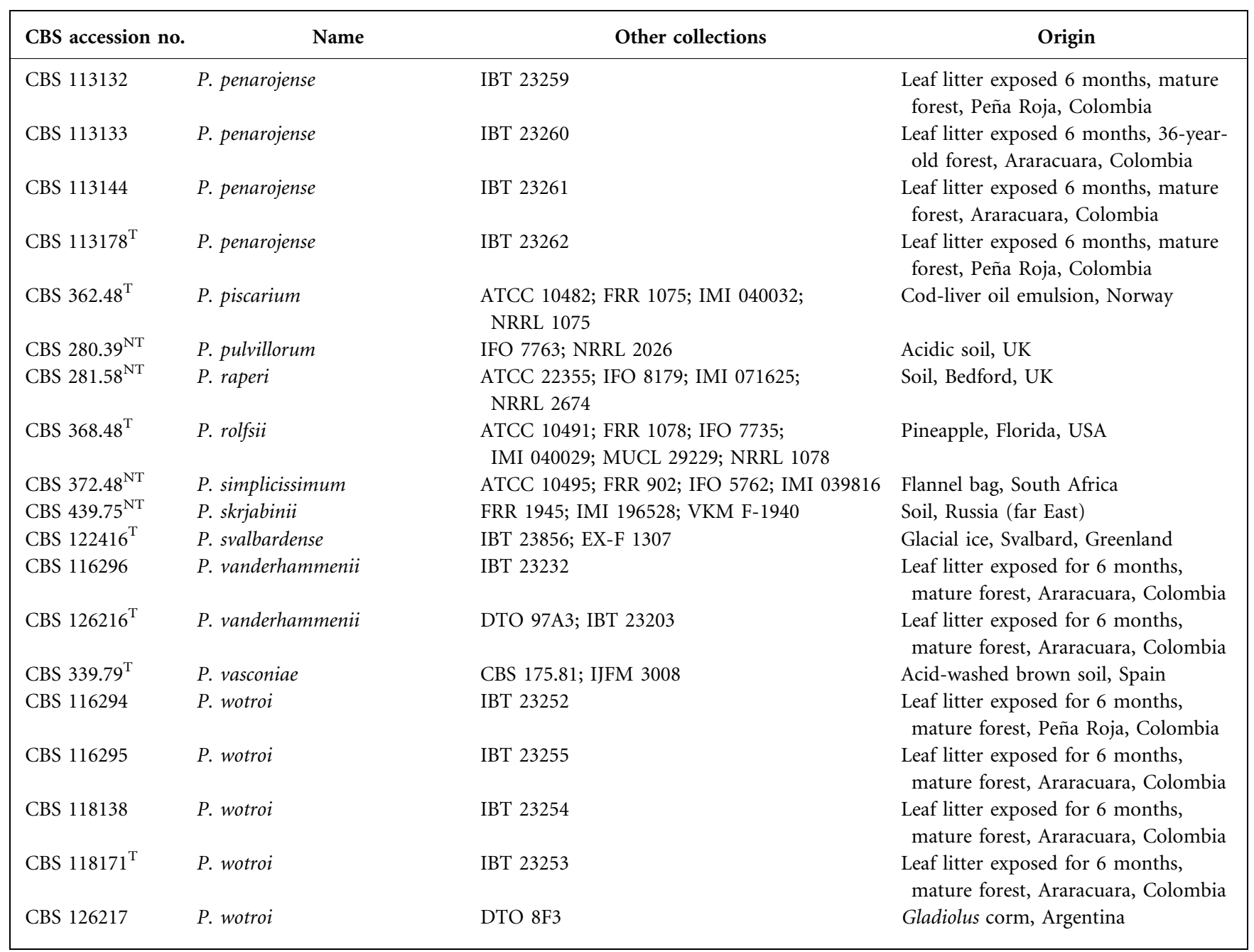

amplified with the primers V9G and LS266 (Gerrits van den Ende \& de Hoog, 1999). Both strands were sequenced using the ABI Prism BigDye Terminator v. 3.0 Ready Reaction Cycle Sequencing kit (Applied Biosystems). Sequence products were purified using a 96-well multiscreen HV plate (Millipore) and Sephadex G-50 superfine columns (Amersham Biosciences). Samples were analysed with a ABI Prism 3700 Genetic Analyzer (Applied Biosystems) and contigs were assembled for the forward and reverse sequences with the SeqMan program from the LaserGene package (DNASTAR).

Phylogenetic analysis. The consensus sequences were aligned using MUSCLE software (Edgar, 2004) and adjusted manually with the CLUSTAL w program in MEGA4 (Thompson et al., 1994; Tamura et al., 2007). Phylogenetic trees were computed with the MEGA4 software, using the maximumparsimony (MP) analysis method. To determine the branch support for each clade, a bootstrap analysis was performed with 1000 replicates. The MP tree was obtained using the Close-Neighbor-Interchange algorithm (Nei \& Kumar, 2000) with search level 3 (Felsenstein, 1985; Nei \& Kumar, 2000) in which the initial trees were obtained with the random addition of sequences (ten replicates). All positions containing gaps and missing data were eliminated from the dataset (complete deletion option). Maximum-likelihood (ML) analysis was conducted using RAxML (randomized accelerated maximum-likelihood) software (Stamatakis et al., 2005) through the CIPRES portal (www.phylo.org). All identical sequences were deleted before the analysis. Newly generated sequences were deposited in GenBank under the accession numbers listed in Fig. 1 and Supplementary Fig. S1 (available in IJSEM Online). In order to get higher bootstrap supports at the nodes, the ITS and tubulin datasets were combined. Before combining these datasets, incongruence between the datasets was detected by comparing reciprocal $70 \%$ bootstrap values obtained by the ML analysis for all gene combinations, using the program COMPAT.PY (Kauff \& Lutzoni, 2002; http://www.lutzonilab. net). Conflicts were considered significant when a taxon was differentially resolved between two gene trees with $>70 \%$ bootstrap support. Finally, the combined dataset was analysed using RAxML, with individual branch length optimization per partition and automatic determination of the number of bootstrap replicates. 


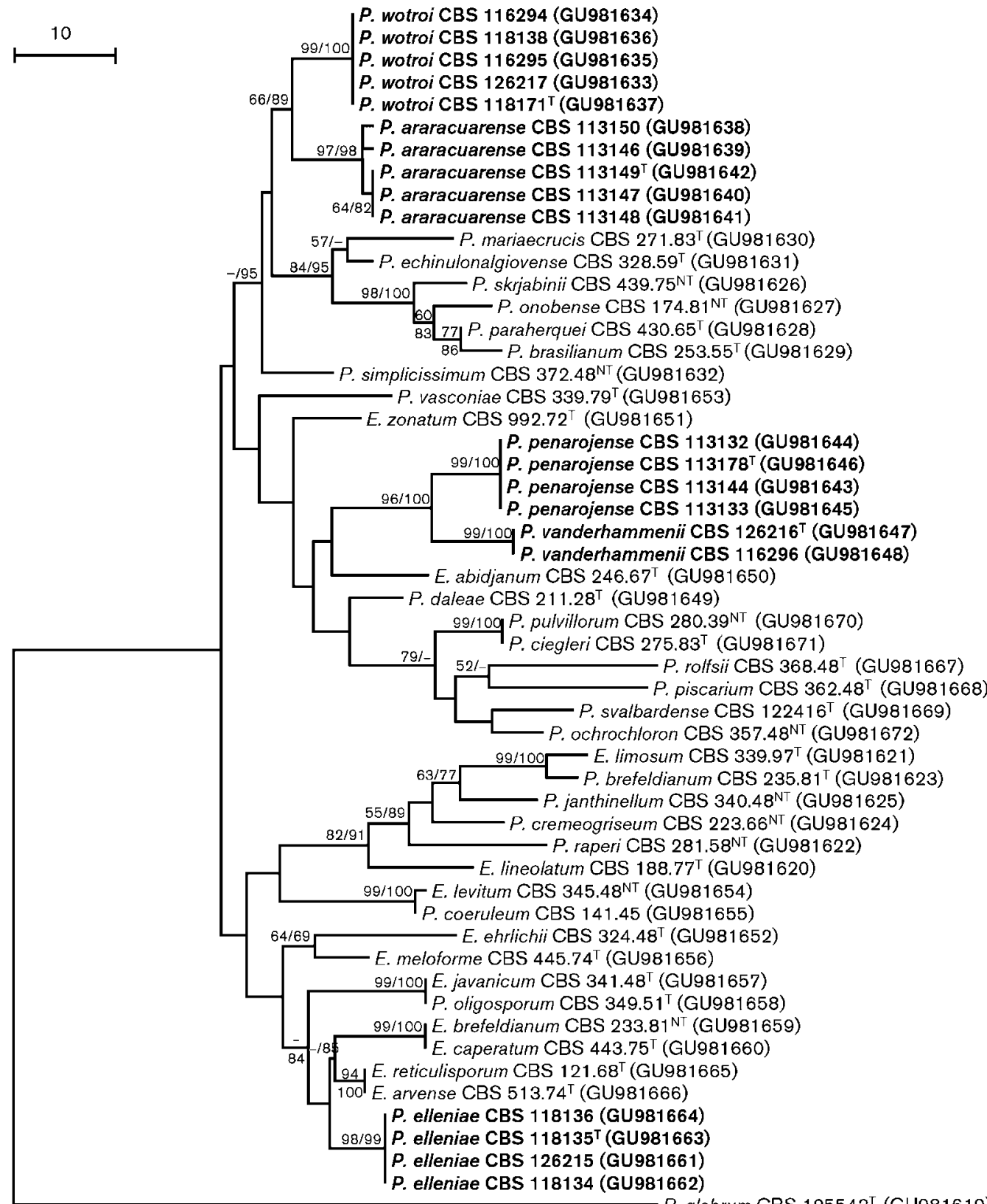

Fig. 1. One of the 25 most parsimonious trees (length 455) based on partial $\beta$-tubulin sequences and depicting the relationship between the novel species and various taxa related to $P$. simplicissimum and $P$. janthinellum. The bootstrap percentages of the $\mathrm{MP}$ analysis (first number) and ML (second number) analysis are given at the nodes. Only bootstrap values $>50 \%$ are shown, and branches supported $<50 \%$ in either the MP or ML analysis are indicated with a hyphen. The novel species are shown in bold and the tree is rooted with P. glabrum. Bar, 10 changes over whole sequence (genetic distance).

\section{RESULTS AND DISCUSSION}

\section{Morphology}

Many Penicillium isolates were obtained during the investigation of different decomposition stages of leaf litter of tropical rain forests in the area along the Caquetá River, Colombia. Combined extrolite, morphological and molecular data showed that many of the Penicillium isolates were related to $P$. simplicissimum and $P$. janthinellum, and represented novel species that are described here. The five novel species shared a high growth rate on CYA and MEA and attained a diameter of $>40 \mathrm{~mm}$ in 7 days. All five novel species grew rather slowly on DG18 medium (15-25 mm). Growth at $37{ }^{\circ} \mathrm{C}$ was a useful characteristic for differentiating the five novel species. 
Penicillium wotroi sp. nov. grew well at $37{ }^{\circ} \mathrm{C}(20-30 \mathrm{~mm})$, Penicillium elleniae sp. nov. grew restrictedly $(0-10 \mathrm{~mm})$ or not at all, while the other three novel species did not grow at $37^{\circ} \mathrm{C}$. Pitt (1979) also observed variation in growth at $37^{\circ} \mathrm{C}$, but he did not find sufficient evidence to use this as a diagnostic feature. In his description of P. simplicissimum, he stated that his isolates from New Zealand and Australian sources did not grow at $37{ }^{\circ} \mathrm{C}$ and that this difference was not sufficient to transfer these isolates to a novel species. Furthermore, growth and $\mathrm{pH}$ reactions on creatine agar were useful characteristics and appeared to be speciesspecific. With the exception of $P$. wotroi sp. nov., all of the other novel species grew moderately to well on creatine agar. Most isolates had weak acid production on creatine agar and acid production was followed by base production in Penicillium penarojense sp. nov., Penicillium vanderhammenii sp. nov. and $P$. elleniae sp. nov. after prolonged incubation for 14 days. Large interspecies variation was observed in conidial morphology and branching patterns. $P$. elleniae sp. nov. formed distinct globose, spinose conidia. The conidia of $P$. penarojense sp. nov. and Penicillium araracuarense sp. nov. were rough-walled, while those of $P$. wotroi sp. nov. and $P$. vanderhammenii sp. nov. were smooth or nearly so. In addition, differences in branching patterns and stipe ornamentation were observed among the five novel species. $P$. araracuarense sp. nov., $P$. vanderhammenii sp. nov. and $P$. elleniae sp. nov. formed sclerotioid structures on oatmeal agar, and ascospores were detected in the latter two species after an incubation period of eight weeks. The ascospores of $P$. elleniae sp. nov. were broadly ellipsoidal with spinose valves and the conidia were distinctly spinose and darkly pigmented. Morphologically, this species resembled Eupenicillium zonatum in many aspects, such as smooth-walled stipes, conidia and ascospore size and ornamentation. However, $E$. zonatum grows rapidly at $37^{\circ} \mathrm{C}$, whereas strains of $P$. elleniae sp. nov. did not grow or had restricted growth at this temperature. The formation of spinose conidia and monoverticillate conidiophores also suggested affinity with Eupenicillium section Pinetora, but members of this section are characterized by the production of flanged ascospores. The colony colour and ascospore size and shape of $P$. vanderhammenii sp. nov. resembled those of Eupenicillium javanicum. However, the stipes of $P$. vanderhammenii sp. nov. were smooth, whereas those of E. javanicum are rough-walled.

\section{Molecular analysis}

Partial $\beta$-tubulin and ITS 1 and 2 regions (including the 5.8S rDNA) were analysed. Phylogenetic analyses of the data were carried out using MP and ML. The phylograms of the two analyses were similar if branches with bootstrap values $<70 \%$ were disregarded as weak or unreliable. The $\beta$-tubulin gene dataset contained 514 characters, of which 178 were parsimony-informative ( $25 \mathrm{MP}$ trees; CI: 0.4723 , RI: 0.7587). The ITS dataset included 559 characters, with 49 parsimony-informative (84 MP trees; CI: 0.4124, RI:
0.7979). The majority of the bootstrap values of the branches of the ITS phylogram were low, indicating that the tree was poorly resolved (see Supplementary Fig. S1 in IJSEM Online).

The ITS and partial $\beta$-tubulin data had sufficient discriminatory power to differentiate the novel taxa from other recognized species. Partial $\beta$-tubulin and combined ITS and $\beta$-tubulin data showed that $P$. vanderhammenii sp. nov. and $P$. penarojense sp. nov. were related to each other with high bootstrap support, as were $P$. wotroi sp. nov. and P. araracuarense sp. nov. (Fig. 1 and Supplementary Fig. S2). Phylogenetically, $P$. elleniae sp. nov. was related to Eupenicillium caperatum, Eupenicillium reticulisporum and E. javanicum and not to any of the anamorphic Penicillia. This suggests that this clade only comprises sexually reproducing species. Both $P$. elleniae sp. nov. and $P$. vanderhammenii sp. nov. formed ascospores after prolonged incubation. Peterson's data (Peterson, 2000) showed that the genera Penicillium and Eupenicillium are a homogeneous monophyletic group and that species related to $P$. simplicissimum and $P$. janthinellum are placed, together with other Penicillia and Eupenicillia, in a clade with $90 \%$ bootstrap value (i.e. Peterson's group 5). Applying the concept of one name for one fungus (Reynolds \& Taylor, 1991), we have chosen to describe these two novel species under their anamorphic names. Although the teleomorph name has precedence in the ICBN, it is more pragmatic to use the genus name Penicillium, since this name is well known and commonly used. It is suggested here that the name Penicillium should be refined to include the perfect state(s) and that only that name should be used in all cases.

$P$. simplicissimum and $P$. janthinellum represent a speciesrich complex of at least 33 recognized species of the genera Penicillium and Eupenicillium, including the five novel species described here. The majority of these Penicillium species were synonymized with $P$. simplicissimum and/or $P$. janthinellum by Pitt (1979) and Stolk \& Samson (1983), but, after molecular studies, appear to be distinct species and should be retained or reinstated. However, there are many other tentative novel species belonging to this complex. In the study of Tuthill et al. (2001), which combined extrolite, morphological and molecular data, three other novel species were shown to belong to this complex. These species were not named and were labelled as 'I', 'II' and 'III'. Representative ITS sequences were included in our ITS phylogram; none of these species resembled our newly described taxa. Furthermore, an ITS sequence of Paecilomyces parvosporus (GenBank accession no. DQ187954) was included in the ITS analysis and our data indicated that this species should be transferred to the genus Penicillium. Although no material of this species was examined, the figure in the original description (Han et al., 2005) shows Furcatum-like Penicillium conidiophores and phialides with long slender necks, which are also typically formed by P. janthinellum (Pitt, 1979). The ITS sequence of an undescribed species, Penicillium geastrivorus (S. W. 
Peterson, unpublished results, GenBank accession no. AF125941), was also included in the phylogram. This sequence was identical to the ITS sequence for the type strain of P. brasilianum CBS 253.55. A large number of Eupenicillia belong to this species-rich group. All members of Eupenicillium section Javanica (i.e. E. javanicum, E. brefeldianum, E. levitum, E. ehrlichii, E. zonatum and E. ludwigii) are linked to this complex. This is unremarkable, because members of this section have, like many related Penicillia, a high growth rate on agar media. However, Eupenicillia from other sections are also related, including E. caperatum, E. reticulisporum (syn. E. arvense), E. meloforme, E. lineolatum, E. limosum, E. meloforme, $P$. vanderhammenii sp. nov. and $P$. elleniae sp. nov. A detailed taxonomic study of this group of Penicillia is necessary to further delimit species boundaries, determine relationships among various species, and reinstate species, such as Penicillium echinulonalgiovense.

\section{Extrolite analysis}

Species of the genus Penicillium belonging to the subgenus Furcatum are efficient producers of metabolites and the extrolite patterns are effective markers for species recognition (Frisvad \& Filtenborg, 1990; Tuthill et al., 2001; Sonjak et al., 2007). We found that each novel species produced unique and characteristic patterns of known and uncharacterized metabolites; an overview is given in Table 2. $P$. vanderhammenii sp. nov. and $P$. penarojense sp. nov. were closely related and both produced paxillin, paspaline, shaerinin/janthitrem and a number of uncharacterized metabolites. This close relationship was also observed in the phylogenetic study. These species could be differentiated by the ability of $P$. vanderhammenii sp. nov. to produce penicillic acid. Penicillic acid is also produced by P. ochrochloron and P. pulvillorum (Frisvad \& Filtenborg, 1990). Pulvilloric acid was produced by $P$. wotroi sp. nov. and this metabolite is also produced by $P$. pulvillorum (syn. P. ciegleri) and P. piscarium (Tuthill et al., 2001). The extrolite data indicate that several metabolites are shared by various species related to $P$. simplicissimum. In this case, it is not the presence of a single extrolite, but rather the pattern of extrolites that is characteristic for a species. Paxillin, paraherquamides, penicillic acid, pulvilloric acid, janthitrems, penitrem A, xanthoepocin, xanthomegnin and viomellein are formed by several species in this clade. This indicates that the biosynthetic genes for the formation of these metabolites are shared by these closely related species.

\section{Ecology}

The new species described in this study were predominantly present in decomposed leaf litter in Amazonia Colombia, However, BLAST searches on GenBank and the internal databases of the CBS-Fungal Biodiversity Centre showed that several of these species were not restricted to Colombian leaf litter. Penicillium wotroi sp. nov. has also been isolated from stored corms of Gladiolus grandiflorus in Mexico (González-Peréz et al., 2009; GenBank accession no. DQ279802) and seeds of Amaranthus hypochondriacus in Mexico (Moreno-Velazquez et al., 2005; DQ026013). P. elleniae sp. nov. has also been isolated from soil in (sub)tropical rainforests of Madagascar and Malaysia. On the other hand, no definitive similarity matches were found for $P$. penarojense sp. nov., $P$. vanderhammenii sp. nov. or $P$. araracuarense sp. nov. The distribution of these species remains unknown, but it is probable that they are not restricted only to Colombian leaf litter.

The presence of a high number of Penicillium species in the decomposed leaf litter suggested that these species may have remarkable properties. In forest soils, where large amounts of plant materials are degraded, Penicillium species are usually detected abundantly, especially members of the Penicillium subgenus Furcatum. This subgenus includes many taxa related to $P$. simplicissimum, which are well-represented and common in hardwood forest soils and grasslands (Christensen et al., 2000). Enzyme mixtures from Penicillia, including those of $P$. simplicissimum and related species (e.g. P. brasilianum), perform well in the hydrolysis of different kinds of lignocellulosic compounds (van Wyk, 1999; Thygesen et al., 2003; Krogh et al., 2004; Song et al., 2010). The novel species described here might also be efficient lignocellulose degraders and represent a new source for cellulolytic and xylanolytic enzymes.

Nutrient analysis of the leaf litter and soil showed that the manganese, copper, zinc, iron and boron contents of the decomposing leaves were relatively high in comparison with the surrounding soils. These cations have also been shown to accumulate during decomposition (unpublished results, C. Lopez-Quintero \& T. Boekhout). P.

Table 2. Overview of extrolites produced by the novel species

\begin{tabular}{|ll|}
\hline Species & \multicolumn{1}{c|}{ Extrolites } \\
\hline P. araracuarense sp. nov. & Pulvilloric acid and several other uncharacterized extrolites \\
P. elleniae sp. nov. & Paxillin, anthraquinones, sorbicillins and several other uncharacterized extrolites \\
P. penarojense sp. nov. & Paxillin, paspaline, shaerinins/janthitrems and several uncharacterized extrolites \\
P. vanderhammenii sp. nov. & Paxillin, paspaline, penicillic acid, shaerinins/janthitrems and several other uncharacterized extrolites \\
P. wotroi sp. nov. & Pulvilloric acid and several other uncharacterized extrolites \\
\hline
\end{tabular}


simplicissimum is tolerant of heavy metals and this species has been proposed as an efficient biosorbent agent in the bioleaching of zinc oxide, copper, lead and nickel (Burgstaller et al., 1992; Li et al., 2008; Valix et al., 2001). Pulvilloric acid and penicillic acid, two extrolites produced by the novel species, can also chelate cations (Weinberg, 1957) and may contribute to this accumulation. Currently, no biochemical studies have been performed on the metabolome of leaf litter and it is unknown whether these chelating extrolites are produced in litter.

\section{TAXONOMY}

\section{Latin diagnosis of Penicillium araracuarense Houbraken, C. López-Q, Frisvad et Samson sp. nov.}

Penicillio simplicissimo affine, sed stipitibus longis, verruculosis, coloniis $37{ }^{\circ} \mathrm{C}$ haud crescentibus, conidiis dilute verruculosis, acore pulvillorica producenti. Typus HUA 170334. MB518025.

\section{Description of Penicillium araracuarense Houbraken, C. López-Q, Frisvad \& Samson sp. nov. (Fig. 2)}

Penicillium araracuarense (a.ra.ra.cu.a.ren'se. N.L. neut. adj. araracuarense of or belonging to Araracuara, department of Caquetá, Colombia, the collection site of the holotype).

Colony diameters, 7 days, in $\mathrm{mm}$ : CYA $25{ }^{\circ} \mathrm{C}$ 38-46; CYA30 ${ }^{\circ} \mathrm{C}$ 41-48; CYA $37{ }^{\circ} \mathrm{C} 0$; MEA 40-51; YES 51-57; DG18 15-22; creatine sucrose agar 23-31, moderate to good growth, weak acid and no base production. No sporulation on CYA after 7 days of incubation, sparse sporulation after 18 days, conidia light grey-green; exudates and soluble pigments absent, colonies moderately sulcate, reverse orange-brown. No or weak sporulation on YES, soluble pigments absent, inconspicuous mycelium, white, reverse orange-red with red centre. Weak sporulation on MEA, becoming strongly lanose in time, dull greygreen conidia with medium red coloured reverse. No reaction with Ehrlich test. Sclerotia produced on oatmeal, sclerotioid, globose, $80-120 \mu \mathrm{m}$ in diameter, buff when
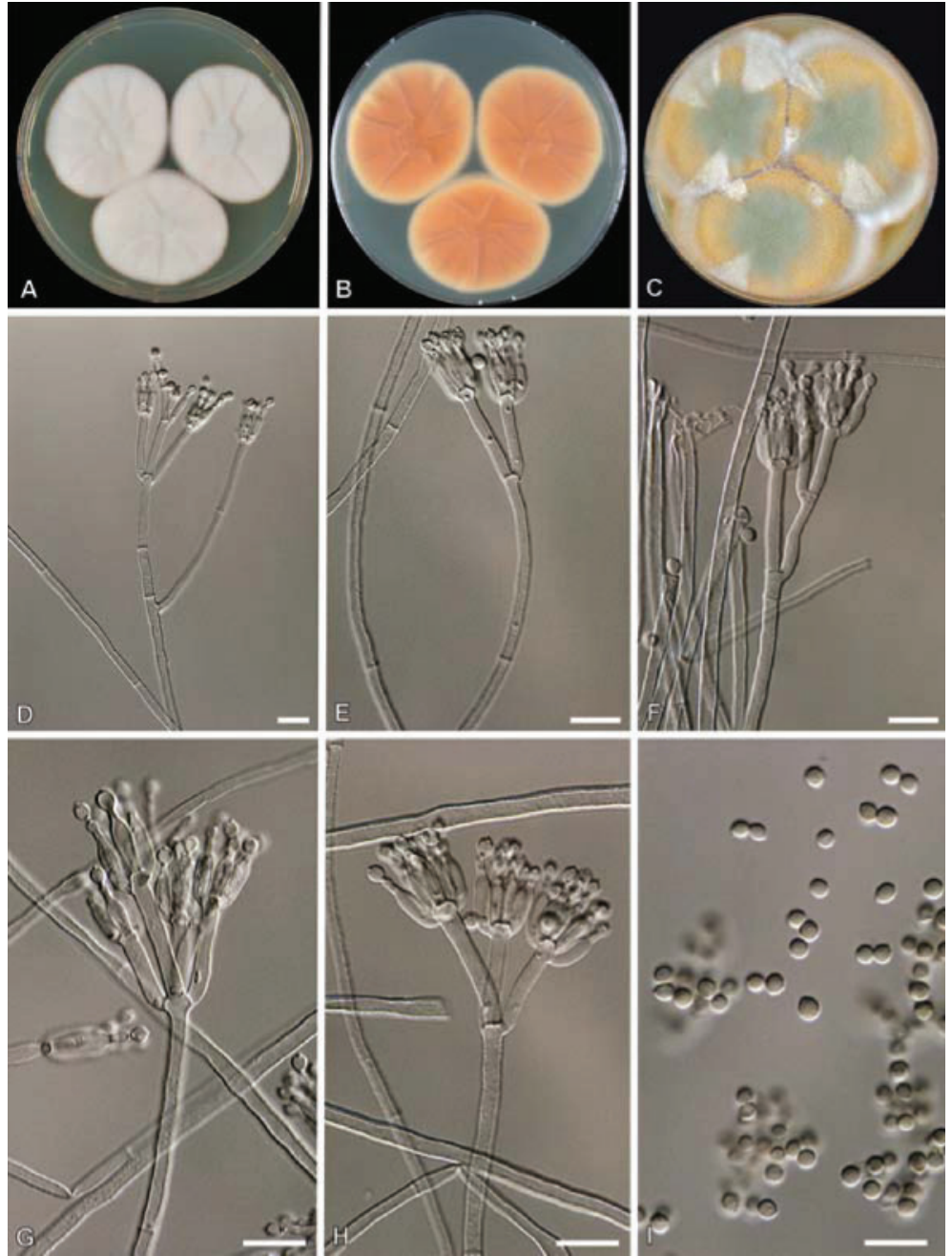
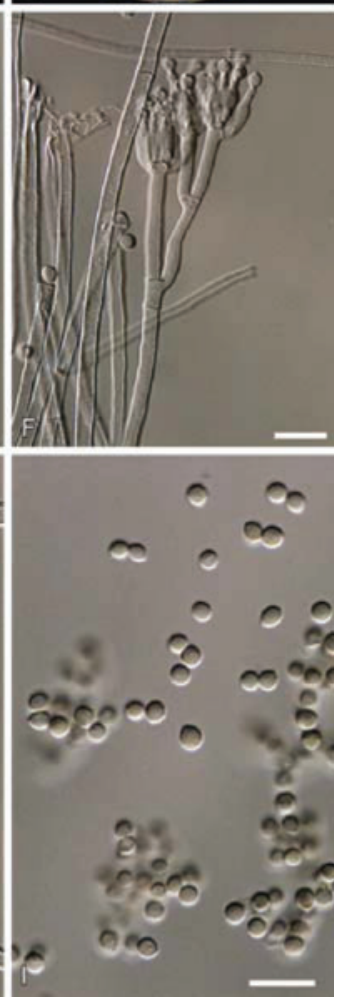

Fig. 2. Penicillium araracuarense sp. nov. (a) Colonies on CYA, obverse; (b) colonies on CYA reverse; (c) colonies on $O A ;(d-h)$ conidiophores; (i) conidia. Bars, $10 \mu \mathrm{m}$. 
young, becoming yellow-brown in age; no ascospores observed after prolonged incubation.

Conidiophores predominantly arising from mycelial mat, biverticillate, with irregular verticils of metulae and occasionally with a divaricate branch; stipes long $(300-600 \times 2.0-$ $3.0 \mu \mathrm{m})$ with rough walls. Metulae unequal in length, terminating in a whorl of 2-3(-5), bearing 5-8 phialides, $(10-) 15-20(-25) \times 2.0-3.0 \mu \mathrm{m}$. Phialides ampuliform to cylindrical, with a distinct neck, 9.0-12 $2.0-3.0 \mu \mathrm{m}$. Conidia subglobose to broadly ellipsoidal, $2.5-3.5(3.0 \pm 0.2) \times$ 2.4-3.0 (2.7 \pm 0.2$) \mu \mathrm{m}$, with finely roughened walls.

Extrolites: Pulvilloric acid and several other unidentified extrolites.

Holotype: HUA $170334^{\mathrm{HT}}$; ex-type cultures are CBS $113149^{\mathrm{T}}$ and IBT $23247^{\mathrm{T}}$, isolated from leaf litter in a leaf litter bag, which was deposited on the forest floor for 6 months, Araracuara, department of Caquetá, Colombia. Mycobank accession no. MB518025.

Ecology: Isolated from leaf litter exposed in a litter bag for 6 months. This species was isolated from various plots of 36-year-old and 48-year-old secondary forests in Araracuara, Colombia (plot4-142; plot3-163b; plot3-164c; plot3-169 and plot 3-186a).

\section{Latin diagnosis of Penicillium elleniae Houbraken, C. López-Q, Frisvad et Samson sp. nov.}

Eupenicillio zonato affine, sed coloniis $37{ }^{\circ} \mathrm{C}$ haud vel vix crescentibus, conidiophoris monoverticillatis, conidiis crassitunicatis, spinulosis; paxillinum, anthraquinona et sorbicillina formantur. Typus HUA 170339. MB518028.

\section{Description of Penicillium elleniae Houbraken, C. López-Q, Frisvad \& Samson sp. nov. (Fig. 3)}

Penicillium elleniae (el.le.ni' a.e. N.L. gen. fem. n. elleniae of Ellen, named in honour of Ellen Hoekstra, formerly a mycologist in the field of Penicillium taxonomy and food mycology).

Colony diameters, 7 days, in mm: CYA25 ${ }^{\circ} \mathrm{C}$ 33-42; CYA30 ${ }^{\circ} \mathrm{C}$ 40-50; CYA37 ${ }^{\circ} \mathrm{C} \quad 0-26$; MEA $40-51$; YES
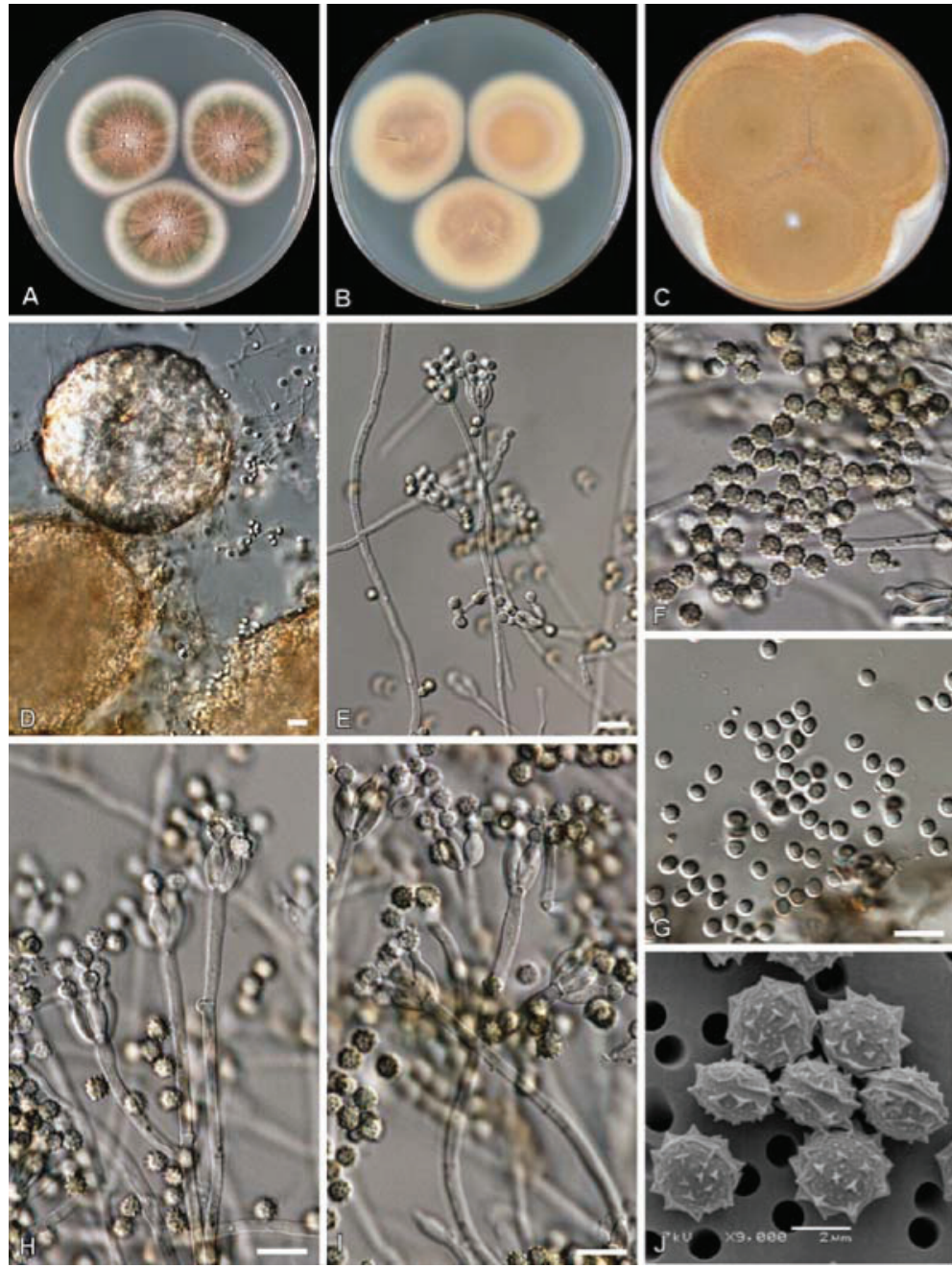

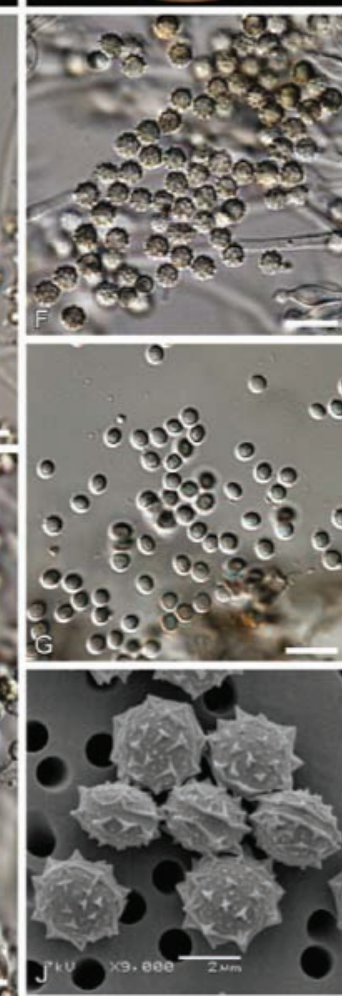

Fig. 3. Penicillium elleniae sp. nov. (a) Colonies on CYA, obverse; (b) colonies on CYA reverse; (c) colonies on OA; (d) ascomata; (e) conidiophores; (f) conidia; (g) ascospores; (h-i) conidiophores; (j) scanning electron micrograph of ascospores. Bars, $10 \mu \mathrm{m}$. 
(30)40-51; DG18 20-30; creatine sucrose agar 15-35, good growth, no or weak acid and delayed base production. Cleistothecia production abundant on CYA after 7 days of incubation, conidiogenesis sparse and inconspicuous, dull green conidia, colonies deep radially sulcate, large exudate droplets in the centre of colony, red-brown, clear or light yellow coloured, reverse yellow with yellow-brown or reddish brown centre, some isolates with cream or beige reverse. No or weak sporulation on YES, mycelium white or light yellow in centre, weak soluble pigments produced, yellow, reverse ranging from cream-light yellow to bright yellow. No reaction with Ehrlich test. Cleistothecia on oatmeal agar yellow-brown (ochre to caramel), 100$200 \mu \mathrm{m}$, sclerotioid, maturing after 3 weeks or more, asci $8-12 \mu \mathrm{m}$ in diameter; ascospores (broadly) ellipsoidal, 3.0$3.5(3.2 \pm 0.1) \times 2.5-3.0(2.6 \pm 0.1) \mu \mathrm{m}$ (without spines), traces of an inconspicuous equatorial ridge, valves spinose to aculeate, $0.2-0.4 \mu \mathrm{m}$ long.

Conidiophores borne from aerial hyphae, mono- and biverticillate, occasionally metulae indistinguishable from monoverticillate stipes. Stipe short, $30-200 \times 2.0-3.0 \mu \mathrm{m}$, smooth-walled. Metulae variable in size, $10-40 \times 2.0-3.0 \mu \mathrm{m}$, bearing 3-7 phialides. Phialides ampulliform with broad

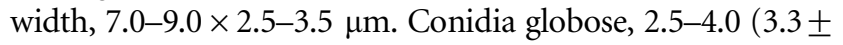
$0.3) \mu \mathrm{m}$, thick-walled, distinctly spinose.

Extrolites: Paxillin, anthraquinones, sorbicillins and several other unidentified metabolites.

Holotype: HUA $170339^{\mathrm{HT}}$; cultures ex-type are CBS $118135^{\mathrm{T}}$ and IBT $23229^{\mathrm{T}}$, isolated from leaf litter in a litter bag, which was deposited on the forest floor for 6 months, Araracuara, department of Caquetá, Colombia. Mycobank accession no. MB518028.

Ecology: Isolated from decomposed leaf litter exposed in a litter bag for 6 months. This species was isolated from 48 year-old and mature forests in Araracuara, Colombia (plots 4-121 and 6-43, respectively) and from a mature forest in Peña Roja, Colombia (plot 'PR'-22).

\section{Latin diagnosis of Penicillium penarojense Houbraken, C. López-Q, Frisvad et Samson sp. nov.}

Penicillii vanderhammenii et $P$. janthinelli affines, sed coloniis in agaro CREA bene crescentibus, sed $37^{\circ} \mathrm{C}$ haud
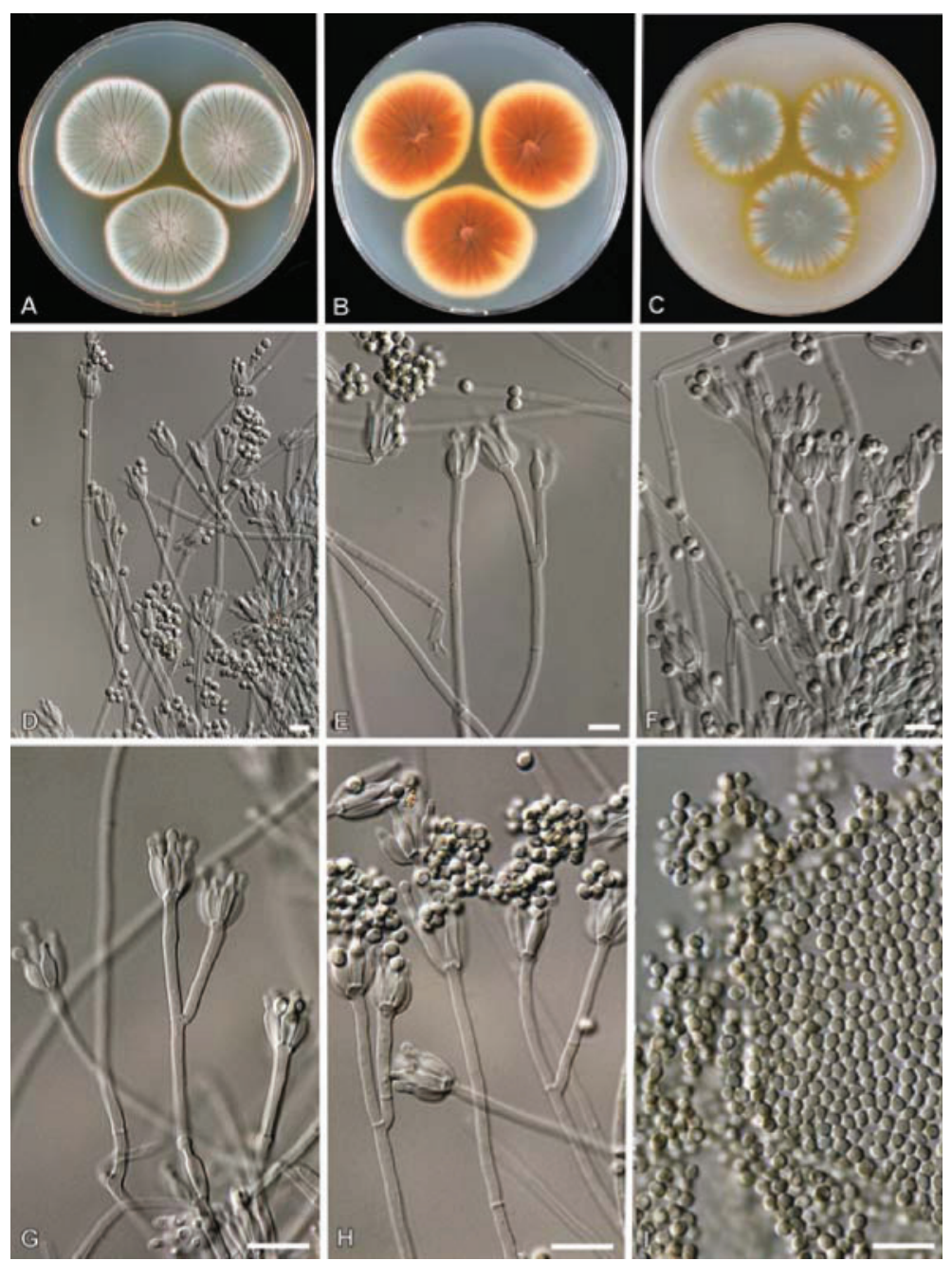

Fig. 4. Penicillium penarojense $\mathrm{sp}$. nov. (a) Colonies on CYA, obverse; (b) colonies on CYA reverse; (c) colonies on $\mathrm{OA}$; $(\mathrm{d}-\mathrm{h})$ conidiophores; (i) conidia. Bars, $10 \mu \mathrm{m}$. 
crescentibus; paxillinum, paspalinum, shaerinina/janthitrema formantur. Typus HUA 170335. MB518024.

\section{Description of Penicillium penarojense Houbraken, C. López-Q, Frisvad \& Samson sp. nov. (Fig. 4)}

Penicillium penarojense (pe.na.ro.jen'se. N.L. neut. adj. penarojense of or belonging to Peña Roja, department of Amazonas, Colombia, the collection site of the holotype).

Colony diameters, 7 days, in mm: CYA25 ${ }^{\circ} \mathrm{C} \quad 40-45$; CYA30 ${ }^{\circ} \mathrm{C} 20-30$; CYA37 ${ }^{\circ} \mathrm{C} 0$; MEA 40-45; YES 35-40; DG18 20-25; creatine sucrose agar 16-25, good growth, variable acid production (absent to moderately present) and base production after prolonged incubation. Good sporulation on CYA after 7 days of incubation, velvety to slightly floccose, conidia grey-green to turquoise-grey, exudates absent, some strains with soluble yellow pigments, radially sulcated colonies, reverse orange-brown or yellowbrown with orange-red centre. Weak sporulation on YES, soluble pigments absent, pale yellow mycelium, reverse orange-red. Colonies on MEA weakly floccose, conidia grey-green, reverse colour like agar medium or in shade of brown. No reaction with Ehrlich test. Sclerotia absent.

Conidiophores predominantly arising from mycelial mat, monoverticillate and biverticillate structures present; stipes long and slender $(200-600 \times 1.5-2.5 \mu \mathrm{m})$, smooth-walled. Metulae, when present, unequal in length, terminating in a whorl of $2(-3)$, occasionally indistinguishable from stipes of monoverticillate conidiophores, bearing 4-8 phialides, $15-25(-30) \times 1.5-2.5 \mu \mathrm{m}$. Phialides ampulliform with a distinct neck, $6.0-9.0 \times 2.0-3.0 \mu \mathrm{m}$. Conidia subglobose, $2.2-3.0(2.6 \pm 0.2) \times 2.0-2.5(2.3 \pm 0.1) \mu \mathrm{m}$, rough-walled.

Extrolites: Paxillin, paspaline, shearinins/janthitrems and several unidentified extrolites.

Holotype: HUA $170335^{\mathrm{HT}}$; cultures ex-type are CBS $113178^{\mathrm{T}}$ and IBT $23262^{\mathrm{T}}$, isolated from leaf litter in a leaf litter bag, which was deposited on the forest floor for 6 months, Peña Roja, department of Amazonas, Colombia. Mycobank accession no. MB518024.

Ecology: Isolated from leaf litter exposed for 6 months in a leaf litter bag. This species was isolated from 36-year-old
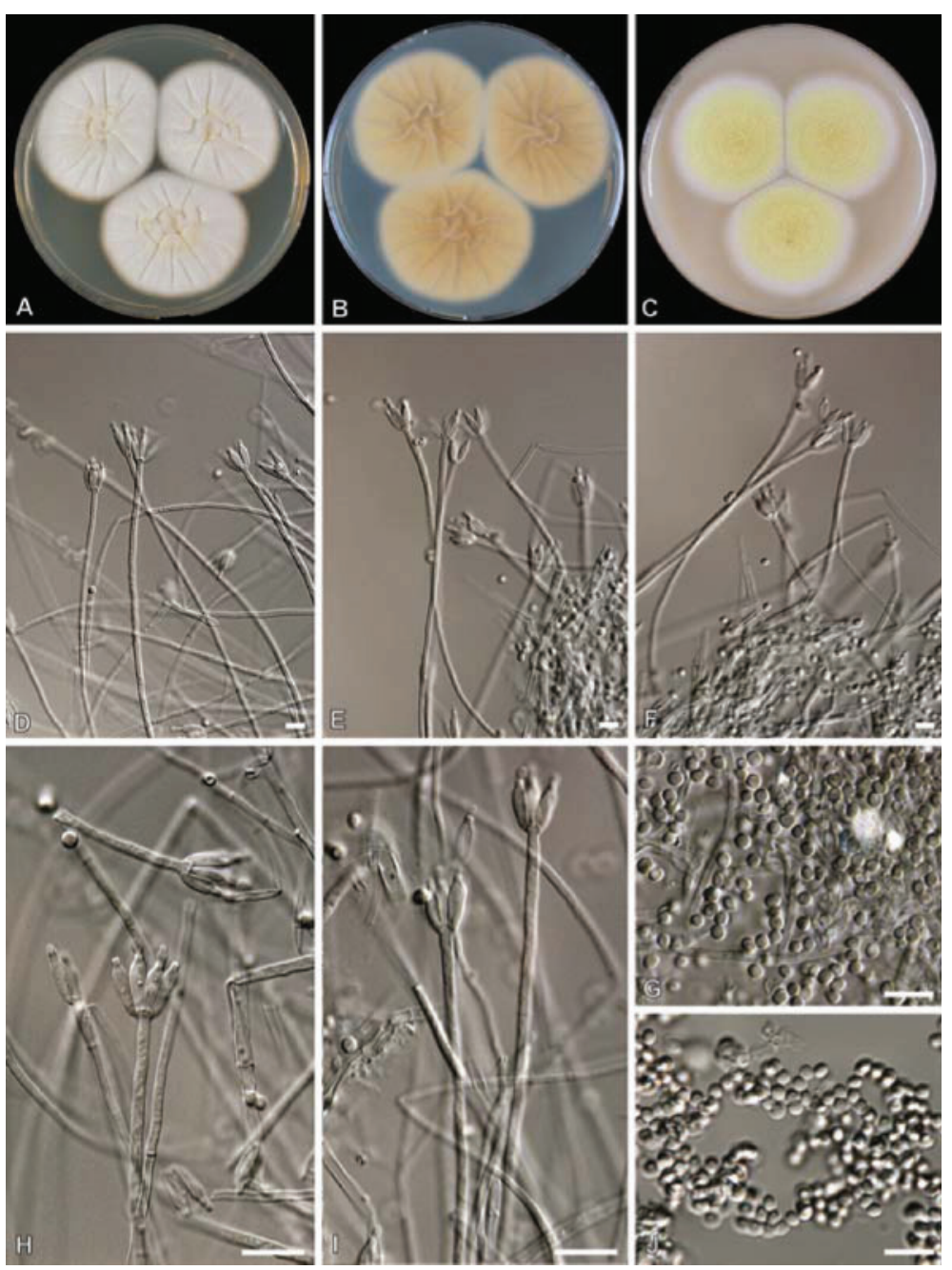

Fig. 5. Penicillium vanderhammenii sp. nov. (a) Colonies on CYA, obverse; (b) colonies on CYA reverse; (c) colonies on OA; $(d, e, f, h)$ conidiophores; (g) conidia; (j) ascospores. Bars, $10 \mu \mathrm{m}$. 
and mature forests in Peña Roja and Araracuara, Colombia (plots 'PR'-49b, 3-167a, 6-75, 'PR'-50a).

\section{Latin diagnosis of Penicillium vanderhammenii Houbraken, C. López-Q, Frisvad et Samson sp. nov.}

Penicillio penarojensi et $P$. janthinello affines, sed cleistotheciis et acore penicillica formantibus. Cleistothecia ochracea; ascosporae minutae, $2.2-2.6 \times 1.8-2.2 \mu \mathrm{m}$. Typus HUA 170337. MB518027.

\section{Description of Penicillium vanderhammenii Houbraken, C. López-Q, Frisvad \& Samson sp. nov. (Fig. 5)}

Penicillium vanderhammenii (van.der.ham.me'ni.i. N.L. gen. masc. n. vanderhammenii of van der Hammen, named in honour of Professor Thomas van der Hammen, an eminent palaeo-ecologist who studied the biodiversity of Colombia).

Colony diameters, 7 days, in $\mathrm{mm}$ : CYA25 ${ }^{\circ} \mathrm{C} \quad 42-49$; CYA30 ${ }^{\circ} \mathrm{C} 40-46$; CYA37 ${ }^{\circ} \mathrm{C} 0$; MEA 45-53; YES 41-47;
DG18 15-20; creatine sucrose agar 16-30, weak, moderate or good growth, weak acid and delayed base production. Conidiogenesis on CYA after 7 days of incubation good, velvety, grey-green conidia, exudate and soluble pigments absent, radially sulcate colonies, reverse beige with dark black-brown centre. Good sporulation on YES, soluble pigments absent, mycelium inconspicuous, white, greygreen conidia, reverse yellow. Colonies on MEA velvety to floccose, grey-green conidia, medium yellow reverse. No reaction with Ehrlich test. Cleistothecia on oatmeal agar ochre, $80-150 \mu \mathrm{m}$, often covered with a network of redbrown hyphae, maturing slowly, after 2 months or more, sclerotioid; asci $8-12 \mu \mathrm{m}$ in diameter; ascospores ellipsoidal, $2.2-2.6(2.4 \pm 0.1) \times 1.8-2.3(2.0 \pm 0.1) \mu \mathrm{m}$ (without spines), traces of an inconspicuous equatorial ridge, valves spinose, $0.2-0.3 \mu \mathrm{m}$ long.

Conidiophores arising from mycelium mat, predominantly monoverticillate, occasionally biverticillate and indistinguishable from stipes of monoverticillate conidiophores. Stipes long, delicate and slender, $200-800 \times 1.5-2.5 \mu \mathrm{m}$, smooth-walled. Phialides ampulliform with distinct neck, $7.0-9.0 \times 2.0-2.5 \mu \mathrm{m}$. Conidia broadly subglobose to
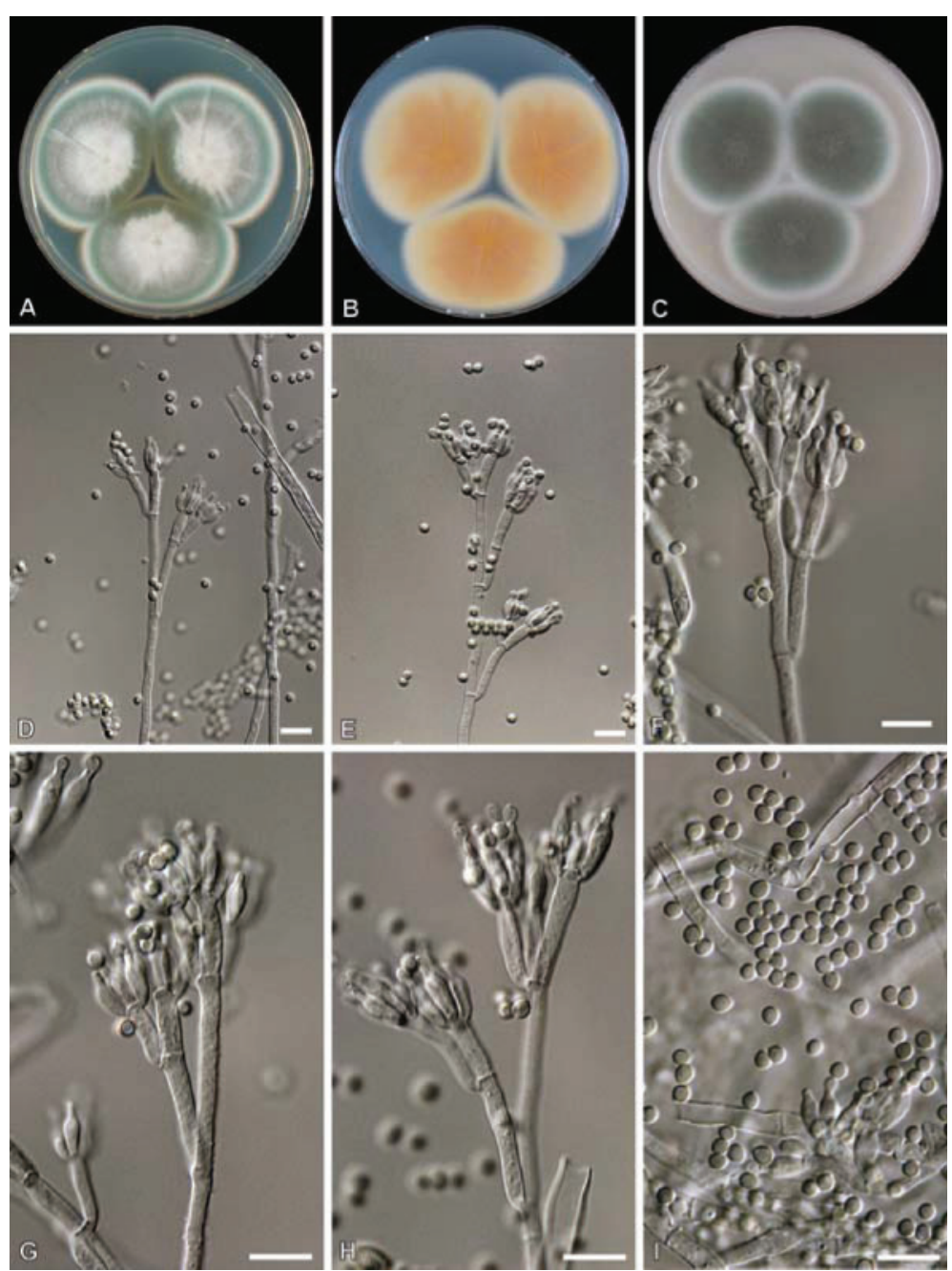

Fig. 6. Penicillium wotroi sp. nov. (a) Colonies on CYA, obverse; (b) colonies on CYA reverse; (c) colonies on $\mathrm{OA}$; $(\mathrm{d}-\mathrm{h})$ conidiophores; (i) conidia. Bars, $10 \mu \mathrm{m}$. 
broadly ellipsoidal, $2.2-3.0 \quad(2.6 \pm 0.2) \times 2.0-2.7 \quad(2.2 \pm$ $0.2) \mu \mathrm{m}$, smooth to very finely rough-walled.

Extrolites: Paxillin, paspaline, penicillic acid, shaerinin/ janthitrem and several other unidentified metabolites.

Holotype: HUA $170337^{\mathrm{HT}}$; cultures ex-type are CBS $126216^{\mathrm{T}}$ and IBT 23203, isolated from leaf litter in a litter bag, which was deposited on the forest floor for 6 months, Araracuara, department of Caquetá, Colombia.

Ecology: Isolated from leaf litter exposed for 6 months in a litter bag (plots 6-91a and 6-95).

\section{Latin diagnosis of Penicillium wotroi Houbraken, C. López-Q, Frisvad et Samson sp. nov.}

Penicillio simplicissimo affine, sed stipitibus longis, verruculosis, coloniis $37{ }^{\circ} \mathrm{C}$ haud crescentibus, conidiis levibus, acore pulvillorica producenti. Typus HUA 170336. MB518026.

\section{Description of Penicillium wotroi Houbraken, C. López-Q, Frisvad \& Samson sp. nov. (Fig. 6)}

Penicillium wotroi (wo.tro'i. N.L. gen. n. wotroi of WOTRO, referring to NWO-WOTRO, the funding organization that supported the project 'Role of fungi during regeneration of Colombian Amazonian forests').

Colony diameters, 7 days, in mm: CYA25 ${ }^{\circ} \mathrm{C}$ 38-50; CYA30 ${ }^{\circ} \mathrm{C}$ 50-60; CYA $37{ }^{\circ} \mathrm{C}$ 20-30; MEA 30-55; YES 3550; DG18 10-20; creatine sucrose agar (10-)20-30, weak growth, no acid or weak acid production, no base production. Conidiogenesis on CYA after 7 days of incubation moderate to good, absent in some isolates, colony surface velvety to floccose, conidia dull green, clear small exudate droplets, soluble pigments absent, weakly sulcate colonies, reverse cream with cream-orange centre. Weak to moderate sporulation on YES, soluble pigments absent, mycelium inconspicuous, white, dull green conidia, soluble pigments absent, reverse beige to light yellow with occasionally a beige-brown centre. Colonies on MEA velvety, dull greygreen, reverse medium coloured. No reaction with Ehrlich test. Sclerotia absent.

Conidiophores arising from mycelial mat, predominantly biverticillate but also many terverticillate structures present, branches divaricate, stipes long, 300-800 $\times 2.5-$ $3.5 \mu \mathrm{m}$, coarsely roughened. Metulae unequal in length, terminating in a whorl of (2)3-6, each bearing 3-8 phialides, $10-20 \times 2.5-3.5 \mu \mathrm{m}$. Phialides ampulliform with a distinct neck, $8.0-10 \times 2.3-3.3 \mu \mathrm{m}$. Conidia subglobose to broadly ellipsoidal, $2.3-3.5 \quad(2.8 \pm 0.2) \times 2.1-2.9$ $(2.0 \pm 0.2) \mu \mathrm{m}$, smooth.

Extrolites: Pulvilloric acid and various other unidentified metabolites.

Holotype: HUA $170336^{\mathrm{HT}}$; cultures ex-type are CBS $118171^{\mathrm{T}}$ and IBT $23253^{\mathrm{T}}$, isolated from leaf litter in a leaf litter bag, which was deposited on the forest floor for
6 months in a mature forest, Araracuara, department of Caquetá, Colombia. Mycobank accession no. MB 518026.

Ecology: Isolated from leaf litter exposed in a leaf litter bag for 6 months. The strains were isolated from mature forests in Peña Roja and Araracuara in Colombia (plots 'PR'-45b, 6-71a, 6-88a and 6-68).

\section{ACKNOWLEDGEMENTS}

We are grateful to NWO-WOTRO for the financial support of the project 'Role of fungi in regeneration forest of Colombian Amazonian' (WOTRO grants 895.100.014 and WB 84-525). Logistical support was also received from Tropenbos Colombia and we thank Dr Carlos Rodriguez. Professor Dr Uwe Braun is thanked for providing the Latin diagnosis of the novel species and Dae-Hoo Kim is thanked for the preparation of the SEM photos. C. L.-Q. and A.E. F. M. thank the University of Antioquia for giving the authors time to collect in the Amazonas and the opportunity to use the laboratory.

\section{REFERENCES}

Aerts, R. (1997). Climate, leaf litter chemistry and leaf litter decomposition in terrestrial ecosystems: a triangular relationship. Oikos 79, 439-449.

Burgstaller, W., Strasser, H., Wöbking, H. \& Schinner, F. (1992). Solubilization of zinc oxide from filter dust with Penicillium simplicissimum: bioreactor leaching and stoichiometry. Environ Sci Technol 26, 340-346.

Christensen, M., Frisvad, J. C. \& Tuthill, D. E. (2000). Penicillium species diversity in soil and some taxonomic and ecological notes. In Integration of Modern Taxonomic Methods for Penicillium and Aspergillus Classification, pp. 309-320. Edited by R. A. Samson \& J. I. Pitt. London, UK: Harwood Academic Publishers.

Duivenvoorden, J. F. \& Lips, J. M. (1998). Mesoscale patterns of tree species diversity in Colombian Amazonia. In Forest biodiversity in North, Central and South America and the Caribbean, pp. 535-549. Edited by F. Dallmeier \& J. A. Comiskey. Carnforth, UK: Arthenon.

Edgar, R. C. (2004). MUSCLE: multiple sequence alignment with high accuracy and high throughput. Nucleic Acids Res 32, 1792-1797.

Felsenstein, J. (1985). Confidence limits on phylogenies: an approach using the bootstrap. Evolution 39, 783-791.

Frisvad, J. C. \& Filtenborg, O. (1990). Revision of Penicillium subgenus Furcatum based on secondary metabolites and conventional characters. In Modern Concepts in Penicillium and Aspergillus Classification, NATO ASI Series A185, pp. 159-172. Edited by R. A. Samson \& J. I. Pitt. New York: Plenum Press.

Frisvad, J. C. \& Thrane, U. (1987). Standardized high-performance liquid chromatography of 182 mycotoxins and other fungal metabolites based on alkylphenone retention indices and UV-VIS spectra (diode array detection). J Chromatogr A 404, 195-214.

Gams, W. \& Domsch, K. H. (1967). Contributions to the soil washing technique for the isolation of soil fungi. Arch Mikrobiol 58, 134-144.

Gentry, A. U. (1996). A field guide to the families and genera of woody plants of Northwest South America (Colombia, Ecuador, Peru) with supplementary notes on herbaceous taxa, 2nd edn. Chicago: The University of Chicago Press.

Gerrits van den Ende, A. H. G. \& de Hoog, G. S. (1999). Variability and molecular diagnostics of the neurotropic species Cladophialophora bantiana. Stud Mycol 43, 151-162. 
Glass, N. L. \& Donaldson, G. C. (1995). Development of primer sets designed for use with the PCR to amplify conserved genes from filamentous ascomycetes. Appl Environ Microbiol 61, 1323-1330.

González-Pérez, E., Yáñez-Morales, M. J., Ortega-Escobar, H. M. \& Velázquez-Mendoza, J. (2009). Comparative analysis among pathogenic fungal species that cause gladiolus (Gladiolus grandiflorus Hort.) corm rot in Mexico. Rev Mex Fitopatol 27, 45-52.

Han, Y., Liang, Z., Chu, H. \& Kang, J. (2005). Paecilomyces parvosporus, a new species with its relatives from Yunnan Province, China. Mycotaxon 94, 357-363.

Kauff, F. \& Lutzoni, F. (2002). Phylogeny of the Gyalectales and Ostropales (Ascomycota, Fungi): among and within order relationships based on nuclear ribosomal RNA small and large subunits. Mol Phylogenet Evol 25, 138-156.

Killham, K. (1994). Soil Ecology. New York: Cambridge University Press.

Krogh, K. B. R., Mørkeberg, A., Jørgensen, H., Frisvad, J. C. \& Olsson, L. (2004). Screening genus Penicillium for producers of cellulolytic and xylanolytic enzymes. Appl Biochem Biotechnol 114, 389-402.

Li, X. M., Liao, D. X., Xu, X. O., Yang, O., Zeng, G. M., Zheng, W. \& Guo, L. (2008). Kinetic studies for the biosorption of lead and copper ions by Penicillium simplicissimum immobilized within loofa sponge. J Hazard Mater 159, 610-615.

Lund, F. (1995). Differentiating Penicillium species by detection of indole metabolites using a filter paper method. Lett Appl Microbiol 20, 228-231.

Maggs, J. (1985). Litter fall and retranslocation of nutrients in a refertilized and prescribed burned Pinus elliottii plantation. For Ecol Manage 12, 253-268.

Moreno-Velazquez, M., Yanez-Morales, M. J., Rojas-Martinez, R. I., Zavaleta-Mejia, E., Trinidad-Santos, A. \& Arellano-Vazquez, J. L. (2005). Fungal diversity in amaranthus (Amaranthus hypochondriacus L.) seed and their molecular characterization. Rev Mex Fitopatol 23, 111-118.

Nei, M. \& Kumar, S. (2000). Molecular Evolution and Phylogenetics. New York: Oxford University Press.

Osono, T. \& Takeda, H. (2002). Comparison of litter decomposing ability among diverse fungi in a cool temperate deciduous forest in Japan. Mycologia 94, 421-427.

Peterson, S. W. (2000). Phylogenetic analysis of Penicillium species based on ITS and LSU-rDNA nucleotide sequences. In Integration of Modern Taxonomic Methods for Penicillium and Aspergillus Classification, pp. 163-178. Edited by R. A. Samson \& J. I. Pitt. New York: Plenum Press.

Pitt, J. I. (1979). The Genus Penicillium and its Teleomorphic States Eupenicillium and Talaromyces. London: Academic Press.

Raper, K. B. \& Thom, C. (1949). Manual of the Penicillia. Baltimore: Williams and Wilkins.

Reynolds, D. R. \& Taylor, J. W. (1991). Nucleic acids and nomenclature: name stability under Article 59. In Improving the
Stability of Names: Needs and Options. Regnum Veg. 123, pp. 171-177. Edited by D. L. Hawksworth. Köningstein, Germany: Koelte Scientific Books.

Richards, B. N. (1987). The Microbiology of Terrestrial Ecosystems. England: Longman Scientific and Technical.

Sáenz, M. S. (1997). Catálogo preliminar comentado de la flora del Medio Caquetá. Tropenbos Colombia (XII).

Smedsgaard, J. (1997). Micro-scale extraction procedure for standardized screening of fungal metabolite production in cultures. J Chromatogr A 760, 264-270.

Song, F., Tian, X., Fan, X. \& He, X. (2010). Decomposing ability of filamentous fungi on litter is involved in a subtropical mixed forest. Mycologia 102, 20-26.

Sonjak, S., Uršič, V., Frisvad, J. C. \& Gunde-Cimerman, N. (2007). Penicillium svalbardense, a new species from Arctic glacial ice. Antonie van Leeuwenhoek 92, 43-51.

Stamatakis, A., Ludwig, T. \& Meier, H. (2005). RAxML-III: a fast program for maximum likelihood-based inference of large phylogenetic trees. Bioinformatics 21, 456-463.

Stolk, A. C. \& Samson, R. A. (1983). The ascomycete genus Eupenicillium and related Penicillium anamorphs. Stud Mycol 23, 144-146.

Tamura, K., Dudley, J., Nei, M. \& Kumar, S. (2007). MEGA4: Molecular evolutionary genetics analysis (MEGA) software version 4.0. Mol Biol Evol 24, 1596-1599.

Thompson, J. D., Higgins, D. G. \& Gibson, T. J. (1994). CLUSTAL W: improving the sensitivity of progressive multiple sequence alignment through sequence weighting, position-specific gap penalties and weight matrix choice. Nucleic Acids Res 22, 4673-4680.

Thygesen, A., Thomsen, A. B., Schmidt, A. S., Jørgensen, H., Ahring, B. K. \& Olsson, L. (2003). Production of cellulose and hemicellulosedegrading enzymes by filamentous fungi cultivated on wet-oxidised wheat straw. Enzyme Microb Technol 32, 606-615.

Tuthill, D. E., Frisvad, J. C. \& Christensen, M. (2001). Systematics of Penicillium simplicissimum based on rDNA sequences, morphology and secondary metabolites. Mycologia 93, 298-308.

Valix, M., Tang, J. Y. \& Malik, R. (2001). Heavy metal tolerance of fungi. Miner Eng 14, 499-505.

van Wyk, J. P. H. (1999). Saccharification of paper products by cellulase from Penicillium funiculosum and Trichoderma reesei. Biomass Bioenergy 16, 239-242.

Vester, H. \& Cleef, A. (1998). Tree architecture and secondary tropical rain forest development. A case study in Araracuara, Colombian Amazonia. Flora 193, 75-97.

Wardle, D. A., Bardgett, R. D., Klironomos, J. N., Setälä, H., van der Putten, W. H. \& Wall, D. H. (2004). Ecological linkages between aboveground and belowground biota. Science 304, 1629-1633.

Weinberg, E. D. (1957). The mutual effects of antimicrobial compounds and metallic cations. Bacteriol Rev 21, 46-68. 